\title{
Budget shock hits Danish universities
}

Sir - Natural sciences faculties in Danish universities are threatened with large reductions in permanent staff. All recruitment of young scientists may come to a full stop, including the transfer of assistant professors to tenure positions, and many scientists in 'permanent' positions can expect to be fired. At the University of Copenhagen about 13 per cent of the staff are expected to be cut.

This is the result of the government budget for 1999. The funding of faculties is based on the number of students. But the support per student varies for historical reasons, without reflecting the costs of experimental work in natural science classes. As a result, the support for each student of natural sciences is markedly lower than that of students in agricultural sciences, medical sciences and civil engineering. The natural sciences have been unable to alter this budgetary arrangement, resulting in a buildup of debt during past years.

Although university professors are expected to divide their time equally between research and teaching, the budget from the state is determined by the number of students, independent of research activity. So a staff reduction of 13 per cent with an unaltered number of students will reduce the time devoted to research by 26 per cent. The faculties have so far protected research and maintained unaltered dimensions of the different science disciplines independent of the fact that some disciplines have many students, while others have comparatively few. Discussions between the Ministry of Research and the faculties have not resolved the inconsistency between budgetary planning and the teaching and research obligations of the staff. Likewise, discussions within faculties have not altered the balance between students and staff in the different disciplines.

The consequences of the cutback are arbitrary and chaotic for individual laboratories irrespective of their teaching load and international research reputation. Small laboratories with research of outstanding international quality tend to have a higher turnover of staff and more new tenure positions coming up and can, therefore, foresee a relatively greater reduction in staff. Some laboratories risk losing new research directions completely.

Many recent examples from all over the world demonstrate that political systems find it difficult to provide the investment and the long-term perspective required for high-quality research. The political focus is on management principles and short-term initiatives with an associated public interest which can keep the party in power and the minister in office. As a result, in the future university researchers may attempt to strengthen their contacts with the political establishment, become more visible in the media, and increasingly emphasize the short-term benefits of research rather than the need for long-term planning.

Kaj Sand-Jensen

Freshwater Biological Laboratory,

University of Copenhagen,

Helsingørsgade 51, DK-3400 Hillerød, Denmark

\section{High priests of science fear for their position}

Sir - I strongly disagree with the tone of your editorial entitled "Ill-advised 'freedom' of scientific information", and with its conclusions (Nature 397, 455; 1999).

First, the new legislation is not a "ruse". It is a public law of the United States. Neither was the legislation inserted secretively or in an underhand manner. The authors publicly announced the measure. Second, the federal Freedom of Information Act exempts from the proposed rule files (data) that would constitute a clearly unwarranted invasion of privacy.

Third, data obtained under that act would not be sequestered. It may be reinterpreted. However it is difficult to see how reinterpretation could be considered disruptive. Reinterpretation of data is an integral part of the scientific process. Surely you are not saying that once a conclusion concerning a data set is reached by an author, that conclusion is inviolate! Were that the case the number of pages in Nature would be significantly reduced. I also question the use of the word "inquisition". One gets the impression that "well-financed special interest groups" conduct inquisitions, whereas academic colleagues conduct research.

Fourth, I do not understand how dissemination of scientific information can stifle freedom. On the contrary, it is only through unhindered dissemination that freedom of expression and debate can flourish.

I suggest that we have here not a concern about academic freedom. Rather it is a concern among some that their special status as high priests of 'science' would be subject to review by the non-anointed, with the possibility that an alternate, perhaps superior, conclusion could be reached. It is also a matter of ownership of intellectual property - that is, greed.

George Lauer

Desert Research Institute,

University of Nevada, 755 E. Flamingo Road,

Las Vegas, Nevada 89132-0040, USA

Harpoons fly in

whale wars

Sir — Frank Cipriano and Stephen Palumbi, in their Scientific Correspondence "Genetic tracking of a protected whale" (Nature 397, 307-308; 1999), should have stuck to scientific arguments and left the anti-whaling propaganda to non-scientific publications [see their reply below]. The hybrid blue/fin whale they examined is not "protected" as they claimed: this word cannot be applied to whales taken under permit for research or under an aboriginal exemption, but only to whales protected from commercial whaling.

Taking any species for scientific research is not a loophole to the protection of whales afforded by the commercial whaling moratorium; it is a right and an obligation applied to all International Whaling Commission (IWC) members by article VIII of the International Convention for the Regulation of Whaling.

IWC resolutions for the genetic testing of whale meat have no legal basis for implementation by IWC. Nevertheless, as Cipriano and Palumbi point out, Norway has already begun to develop a genetic database for minke whales taken by its whalers. Japan is developing a genetic database for all marine mammals landed in the country, whether from small cetacean catches, strandings, or as a result of research.

Cipriano and Palumbi's statement “Thus \#26 was killed despite a global moratorium on commercial whaling, and evaded a strict system for the international traffic in protected species..." is provocative, given that this killing, as all agree, was legal. Japan does not permit the import of whale meat from countries that are not IWC members. Iceland resigned from the IWC and is no longer eligible to export whale products to Japan. Norway has prohibited exports of whale meat products.

Cipriano and Palumbi also strayed into propaganda with their statement that "more than 1,000 minke whales are killed each year by IWC members... despite the 
moratorium". But the moratorium does not apply to whales taken under scientific permit; nor to IWC members that filed objections to it (Norway); nor to whales allocated by the IWC for aboriginal whaling (Greenland, US and Russian Inuits, and so on). The authors also did not mention that 1,000 minkes annually are hardly a statistical blip in a population of more than one million. And they did not explain why they concluded that a "genetic monitoring programme is necessary" because 1,000 minke whales were taken legally.

Finally, Cipriano and Palumbi are wrong to characterize legal rights and obligations as "loopholes... large enough for protected whales to slip through". The catch and identification of a blue/fin hybrid whale advanced scientific knowledge of a species interaction that most scientists had not thought possible. Similarly, the Japanese discovery of a pygmy minke whale species and its minke stock identifications in the Antarctic were significant contributions to science. Would Cipriano and Palumbi ban this type of science to close their "loophole"?

As for the Convention on International Trade in Endangered Species (CITES), more countries would support it if it were more scientifically based and less driven by animal-rights lobbyists. That is why most countries are now trying to reform it.

Alan Macnow

Japan Whaling Association,

321 East 53 Street, New York 10022, USA

Palumbi and Cipriano reply - In our view, Macnow does not advance the debate about the role of genetics in whaling or deal with the substantial issues that face efforts to manage international marine resources, nor does he question our results. Our data show how genetic techniques can lead to a positive identification of a particular whale sample. Such an identification system provides the ability to trace an individual from ocean to retail market. This pathway is the focus of all international efforts to manage whaling, but it has never been directly observed until now. Instead, typical management efforts use indirect measures of stock levels and total fishery impact.

The points raised by the Japan Whaling Association via Macnow's letter do not address these issues. Rather, the main point seems to be that whales are not protected because mechanisms such as scientific whaling exist to allow countries to ignore IWC restrictions. Yet the mere fact that a permit is required to conduct scientific whaling shows that the IWC intends to protect species that have been overexploited until populations have recovered.

It may be that the association wishes to conclude that no whale is protected once it has been targeted by a scientific whaling operation because such operations have no clear bounds. The loose regulations on scientific whaling have been the subject of much debate in the IWC, in Nature and elsewhere. Despite the provisions for scientific whaling, IWC and CITES regulations are clearly designed to protect whale stocks from overexploitation. Macnow's opinion that no whales are "protected" is ironically close to our own point that current international regulations allow individuals of species in need of protection to be killed and sold legally.

Macnow also does not accurately represent our call for genetic databases. Our market surveys since 1993 have shown many species available in markets, not just the minke whales taken for research. We recommend a genetic monitoring programme precisely because it is impossible to prove that these whales come from illegal sources without a genetic database of legally taken whales.

However, we are very encouraged by the promise of the Japan Whaling Association not to allow the import of whale products from Iceland, especially after Iceland's decision on 10 March to resume commercial whaling.

Finally, Macnow implies that much scientific whaling is done for valid experimental purposes. This is an important but controversial topic, and Macnow does not provide any solid evidence of the value of data gathered. In fact, non-lethal methods of research have developed quickly over the past decade, and have supplanted the need to kill whales in many instances. Genetic samples from skin biopsies, sloughed skin or even faeces now provide a wealth of information about stock structure that in the past has been provided by liver samples from scientific hunts. Steve Palumbi, Frank Cipriano

Department of Organismic and Evolutionary Biology, Harvard University, BioLabs, 16 Divinity Avenue, Cambridge, Massachusetts 02138, USA

\section{System values seniority over innovation}

Sir - As a postdoctoral researcher I can identify with many of the feelings expressed in your poll of postdocs (Nature 397, $640-641 ; 1999)$. My biggest frustration is with the problem of obtaining external funding. I am sick of having to use a professor's name on research proposals to get them funded.

If I want the all-important funding I have to donate my ideas to a more senior researcher. I receive no recognition, and my control of the budget, and therefore the research design and implementation, is reduced. I currently work in Sweden, and my friends in Britain mirror my concerns.

It seems that funding councils, staffed by senior researchers, impose a system in which seniority overrides innovation and enthusiasm, and young researchers are open to exploitation. Presumably, should I reach those dizzy heights, I will be expected to boost my research profile in the same way. The system blocks my ideas and career development for those of a professor who, incidentally, I have no doubt is in sympathy with my concerns.

I. A. Brown

Climate Impacts Research Centre, Björkplan 6a, 98142 Kiruna, Sweden

\section{Curb abuses in graduate school}

Sir - Carl Djerassi's Commentary makes the most insightful and useful suggestion I have seen on the issue of mentoring in graduate school (Nature 397, 291; 1999).

Djerassi calls for the candid evaluation of professors as research administrators and mentors, a proposal that might genuinely improve the lives of graduate students. $\mathrm{He}$ has taken a bold step in addressing this issue squarely and honestly.

I am in a graduate programme at Harvard University that has long employed advisory committees, and the difficulties with them are exactly as Djerassi says. Senior members of faculty hold complete sway over these committees, and other committee members contest the opinion of these individuals at their peril. The committee system is in no way independent or objective, nor does it provide the opportunity to discern, let alone to correct, conflicts or deficiencies in the working relationship between professors and graduate students.

It is widely agreed among graduate students here that Jason Altom would have been no better off with a committee than he was without one. Perhaps this is also recognized by faculty members, but Djerassi is the first to acknowledge it in my experience.

Many students will suffer in their careers, or be driven to abandon science altogether, because of difficulties and abuses in graduate school. In addition to the personal suffering that this engenders, it is an enormous waste of scientific talent. Any effort to provide graduate students with fair, reasonable and considerate advice will not only improve their lot but will be positively reflected in the manner in which they conduct themselves throughout their careers and in their relationships with colleagues and students of their own.

Name and address supplied 